\title{
APPLICATION OF PATTERN RECOGNITION METHODS TO AUTOMATIC IDENTIFICATION OF MICROSCOPIC IMAGES OF ROCKS REGISTERED UNDER DIFFERENT POLARIZATION AND LIGHTING CONDITIONS
}

\author{
Bartlomiej ŚLIPEK \& Mariusz MLYNARCZUK \\ AGH University of Science and Technology, Faculty of Geology, \\ Geophysics and Environmental Protection; \\ al. Mickiewicza 30, 30-059 Krakow, Poland; \\ e-mail:mlynar@agh.edu.pl
}

\begin{abstract}
The paper presents the results of the automatic classification of rock images, taken under an optical microscope under different lighting conditions and with different polarization angles. The classification was conducted with the use of four pattern recognition methods: nearest neighbor, k-nearest neighbors, nearest mode, and optimal spherical neighborhoods on thin sections of five selected rocks. During research the CIELAB color space and the 9D feature space were used. The results indicate that changing both lighting conditions and polarization angles results in worsening the classification outcome, although not substantially. Duduring the automatic classification of rocks photographed under different lighting and polarization conditions, the highest number of correctly classified rocks $(97 \%)$ is given by the nearest neighbor method. The results show that the automatic classification of rocks is possible within a pre-defined group of rocks. The results also indicate the optimal spherical neighborhoods method to be the safest method out of those tested, which means that it returns the lowest number of incorrect classifications.
\end{abstract}

Key words: pattern recognition, automatic rock classification, image processing 


\section{INTRODUCTION}

\section{Pattern recognition and artificial intelligence}

Pattern recognition is a classic and one of the oldest branches of artificial intelligence. The concept of artificial intelligence provides a mimicking the operations done by a human brain, with the use of computers (Tadusiewicz \& Flasiński 1991). The idea of pattern recognition is based on classifying an unknown object into a pre-defined class of objects. A class can also be defined as a group of microscopic images of a given rock as presented in this paper.

\section{Usage of pattern recognition in various fields}

Pattern recognition is extensively used in various aspects of science and everyday life, also in Earth sciences. The examples in geophysics include the work of Messina \&Langer (2011), in which they describe a constant method of monitoring volcanic activity, the paper of Dzwinel et al. (2006), who present a usage of Kohonen self-organizing neural networks in seismic record classification, the paper of Jarzyna et al. (2007) describing the usage of neural networks in recreating geophysical well logging, and the paper of Mastej (2011), in which author attempts the neural network aided pattern recognition in a combined interpretation of magnetotelluric AMT and CSAMT surveys from the Grabownica oil and gas field.

Artificial intelligence methods also found their use in geology. Marshallinger (1997) took macroscopic pictures of polished rock samples using a flat scanner. Next, the pictures were analyzed using special algorithms, which led to a $90 \%$ correct identification. In an experiment of Marmo et al. (2005), the authors investigated images of ancient carbonate rocks. The images were automatically recognized, which resulted in successful defining their textures. Młynarczuk (2010) used the results obtained with profilometric laser measurements as the input data for pattern image recognition methods. The research provided a $98 \%$ accurate classification of the rocks studied, based on a rock fracture roughness. Młynarczuk et al. (2012) tested pattern recognition algorithms to automatic classifying microscopic pictures of thin sections of selected rocks. The results, reaching a $99 \%$ correct classification, were a starting point for further research, whose results are presented in this paper. The focus is placed on the fact that while macroscopic rock photographs taken under natural conditions will always be burdened with different sun lighting (e.g. Dunlop 2006, Ślipek et al. 2013), microscopic classification under unified lighting conditions can significantly contribute to high percentages of correct recognitions.

\section{The goal of experiment}

The goal of the experiment was researching the pattern recognition algorithms in the case, when the identification of thin sections is conducted in an environment with changing lighting and polarization conditions. 


\section{Feature space}

Every recognizable object has its numerical description, which consists of a specific, given number of parameters, i.e., the so-called feature vector. The parameters chosen for the recognition process define a certain space, known as the feature space. Its dimensions refer to the number of the selected parameters that describe the objects. A parameter of a feature space can be represented by any measurable value, which describes the objects analyzed. Choosing the appropriate feature space is an important problem of the automatic classification.

The authors used a nine-dimensional feature space:

1) mean gray level on the first color channel,

2) mean gray level on the second color channel,

3) mean gray level on the third color channel,

4) mean gray level of the morphological gradient obtained for the first color channel,

5) mean gray level of the morphological gradient obtained for the second color channel,

6) mean gray level of the morphological gradient obtained for the third color channel,

7) the variogram sill obtained for the first channel,

8) the variogram sill obtained for the second channel,

9) the variogram sill obtained for the third channel.

To prevent the domination of some features, the data were normalized in the $0-1$ range. The photographs were taken in the RGB color space but, based on the papers of Górszczyk (2012) and Obara (2007), the RGB color space was next transposed to the CIELAB color space as it should provide a better object classification.

\section{Training set}

A training set consists of a group of property vectors of exemplary objects that have a correct classification. Due to the fact that the algorithm does not have an a priori knowledge of the object classification, its specification must be installed in the computer memory with the use of the training set (Tadeusiewicz \& Flasiński 1991).

\section{Pattern recognition methods}

The authors used four pattern recognition methods:

1) The nearest neighbor method $(\mathrm{NN})$,

2) The $k$-nearest neighbor method $(\mathrm{kNN})$, for $k=3$,

3) The nearest mode method (NM),

4) The optimal spherical neighborhoods method (OSN).

The $\mathrm{NN}$ and $\mathrm{kNN}$ are minimal-distance methods. Essentially, they measure the distance between the object being classified and the training set elements, and classify the object to the class to which the distance measured is minimal. The NM and OSN methods 
are based on a pattern, which can be defined in various ways. The fundamental role of an identifying algorithm is determining whether an object belongs to one of the patterns that describe the given class, or it is located closest to the class. The NM method replaces a complete class in a training set with a single element; i.e., with the mode of a given class.

In this paper the mode is defined by arithmetic mean of each feature calculated for each individual class. In the OSN method, each element of the training set is surrounded by an $n$-dimensional sphere. The sphere radius is calculated for each individual element, and the classification is based on determining whether a property vector of an unknown object is located within this sphere.

\section{ROCKS INVESTIGATED}

The investigations were conducted on five rock types with very different petrographic, mechanical and physical properties. The images were registered for the following rocks (Fig. 1): granite from Strzelin, sandstone from Tumlin, dolomite from Rędziny, limestone from Czatkowice, and porphyry from Miękinia.

Thin sections were observed under a Zeiss polarization microscope under different lighting and polarization conditions. When recording the images, three different types of lighting (optimal, slightly overexposed, slightly underexposed) were used applying three different positions of polarizers: one polarizer only, and two polarizers but crossed under the angles $45^{\circ}$ and $90^{\circ}$. Such a setup enabled nine parameter combinations. For each of them ten photographs of random thin section areas were taken. Ten additional areas were photographed for random setup of acquisition parameters. This approach enabled capturing 300 images under different lighting and polarization conditions.

The images (examples are shown in Figure 1), with a resolution of $1280 \times 960$ pixels, were saved in a lossless TIFF format. Additional 300 photographs were taken under static lighting and polarization conditions (optimal lighting and one polarizer). These images were a reference material in analyzing the impact of different acquisition conditions on rock classification.

\section{RESULTS}

In the experiment, the training set consisted of 50 randomly picked images for each of the five rocks analyzed, giving a total of 250 images. It is important to point out that the training set is not part of the image set subject to recognition. It means that there is no possibility of an image being compared with itself.

For the purpose of proper results quality, the operation of picking the training sets was conducted 500 times for each pattern recognition method. The results are presented as an average of 500 random training set picking operations.

Note that the methods will result in one of the three possibilities: correct recognition, incorrect recognition, or information "no classification" (meaning that the recognition has been impossible). 

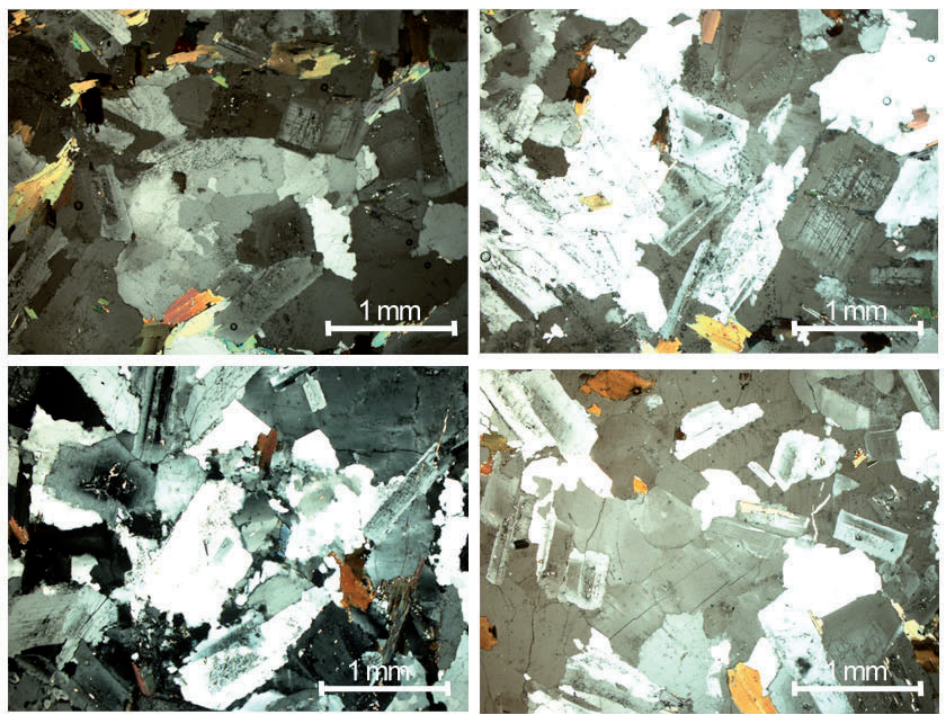

Granite from Strzelin
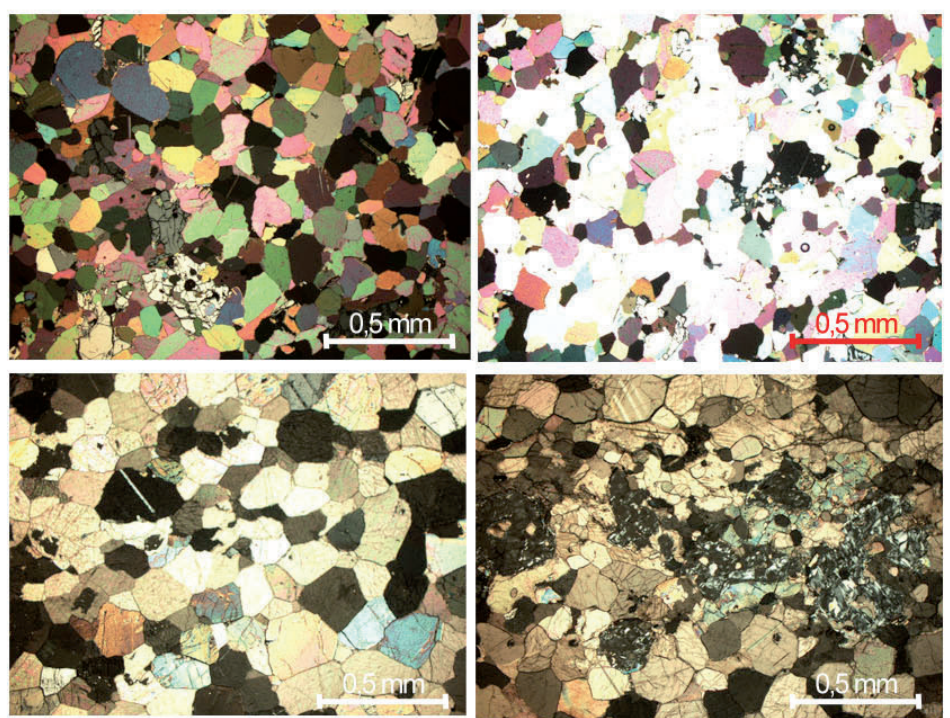

Dolomite from Rędziny
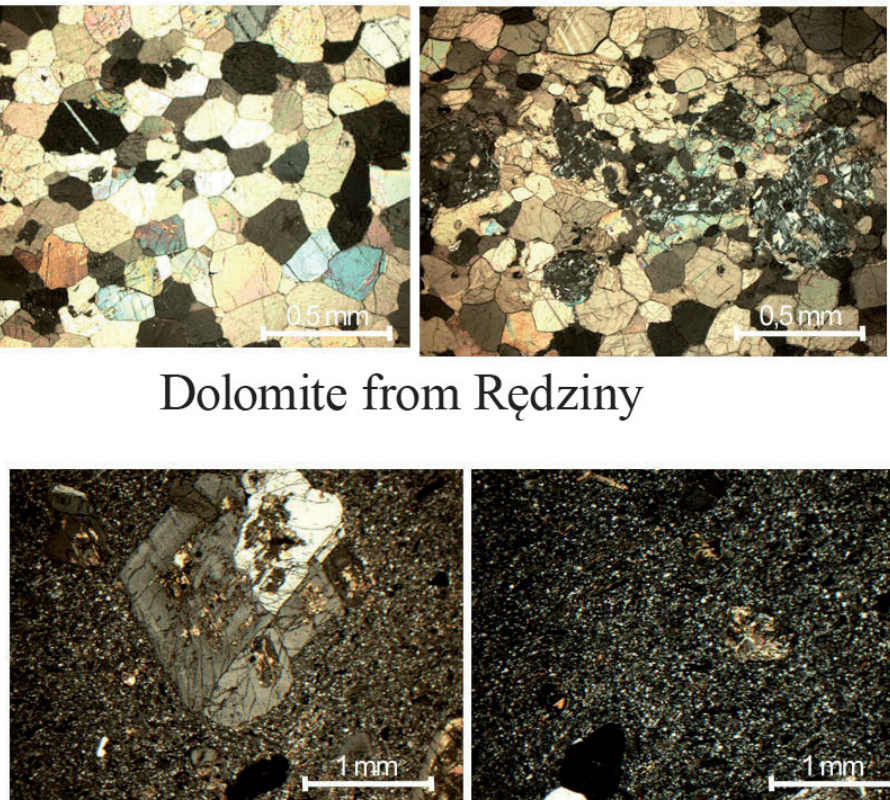

0,
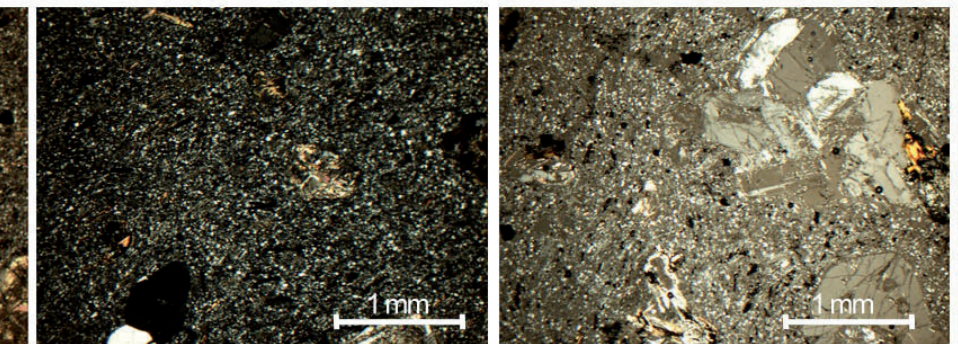

Porphyry from Miękinia
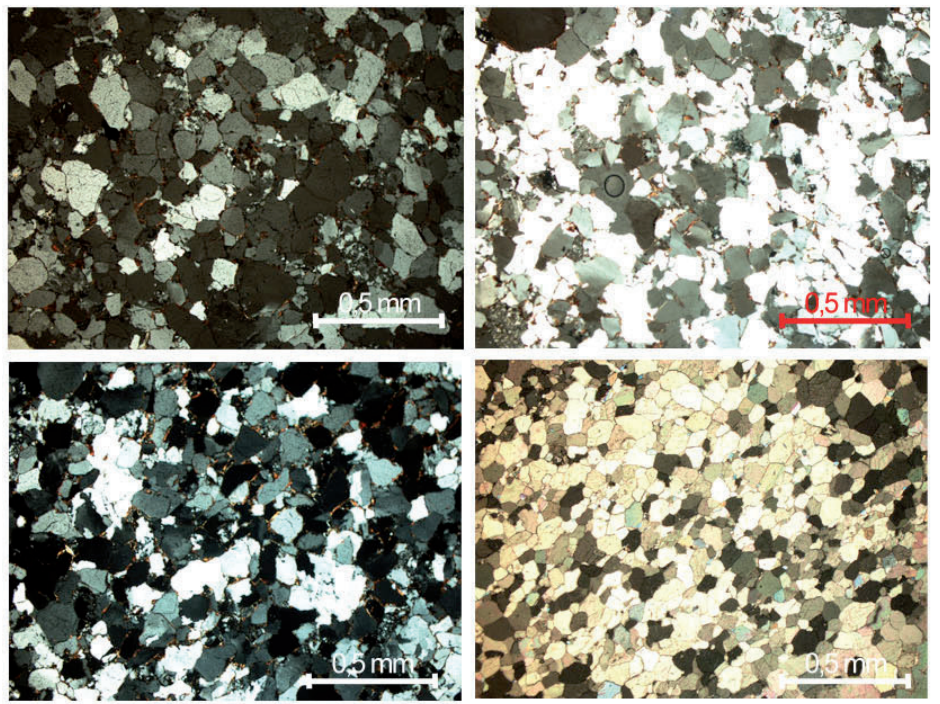

Sandstone from Tumlin
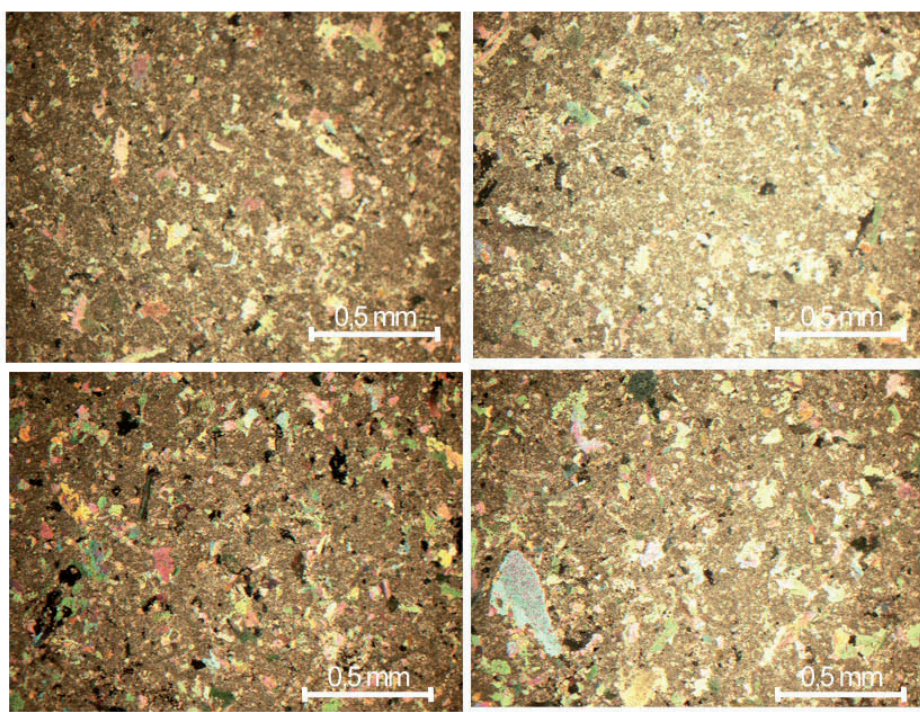

Limestone from Czatkowice

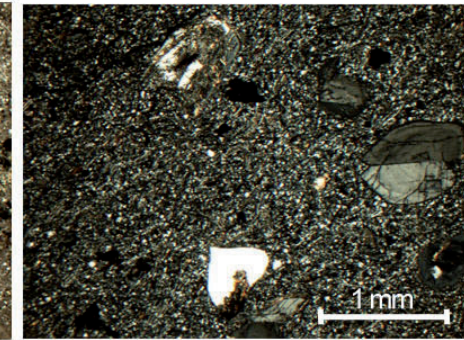

Fig. 1. Sample images of rocks selected for the test, photographed under different acquisition conditions (images taken with a random combination of illumination and orientation of polarizers) 


\section{Correct recognition level}

Correct recognition informs about a number of correctly classified objects. The highest effectiveness of recognition (Fig. 2) belongs to the NN method with a total of $99.61 \%$ correctly recognized samples under static (not changing) lighting and polarization conditions. It also yields the best results $(97.07 \%)$ for samples photographed under different acquisition conditions. The worst algorithm under static lighting and polarization conditions is the NM method $-98.35 \%$, while under different lighting conditions, the least effective algorithm is the OSN method $-81.11 \%$.

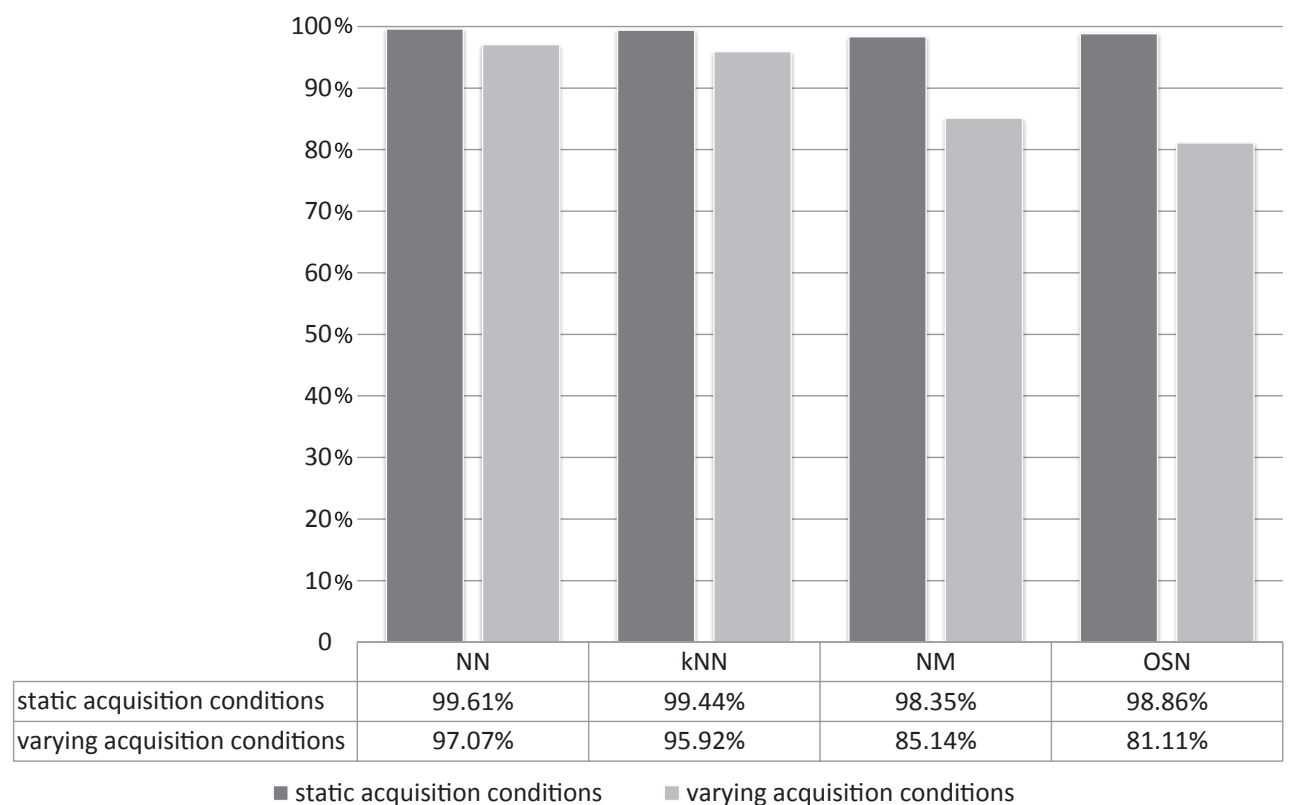

Fig. 2. Averaged level of correct classifications for 500 iterations of the algorithm

During the recognition process, the training set was picked randomly. Although in practice the training set should consist of elements most representative of each class, this kind of approach ensures the best classification results (Tadeusiewicz \& Flasiński 1991).

The best results were achieved in the NN method with the use of the best (of randomly selected) training set: the correct classification results were $99.98 \%$ for static lighting and polarization conditions and $99.12 \%$ for changing lighting and polarization conditions. The worst results under the static lighting and polarization conditions provided the NM method $-99.28 \%$. For different lighting and polarization conditions, the OSN method faired worst with a result of $86.06 \%$. 


\section{Incorrect recognition level}

The worst performance belongs to the NM method, which under different acquisition conditions gave a result of $14.86 \%$ incorrect recognitions. The result is clearly inferior compared to other methods presented in Figure 3.

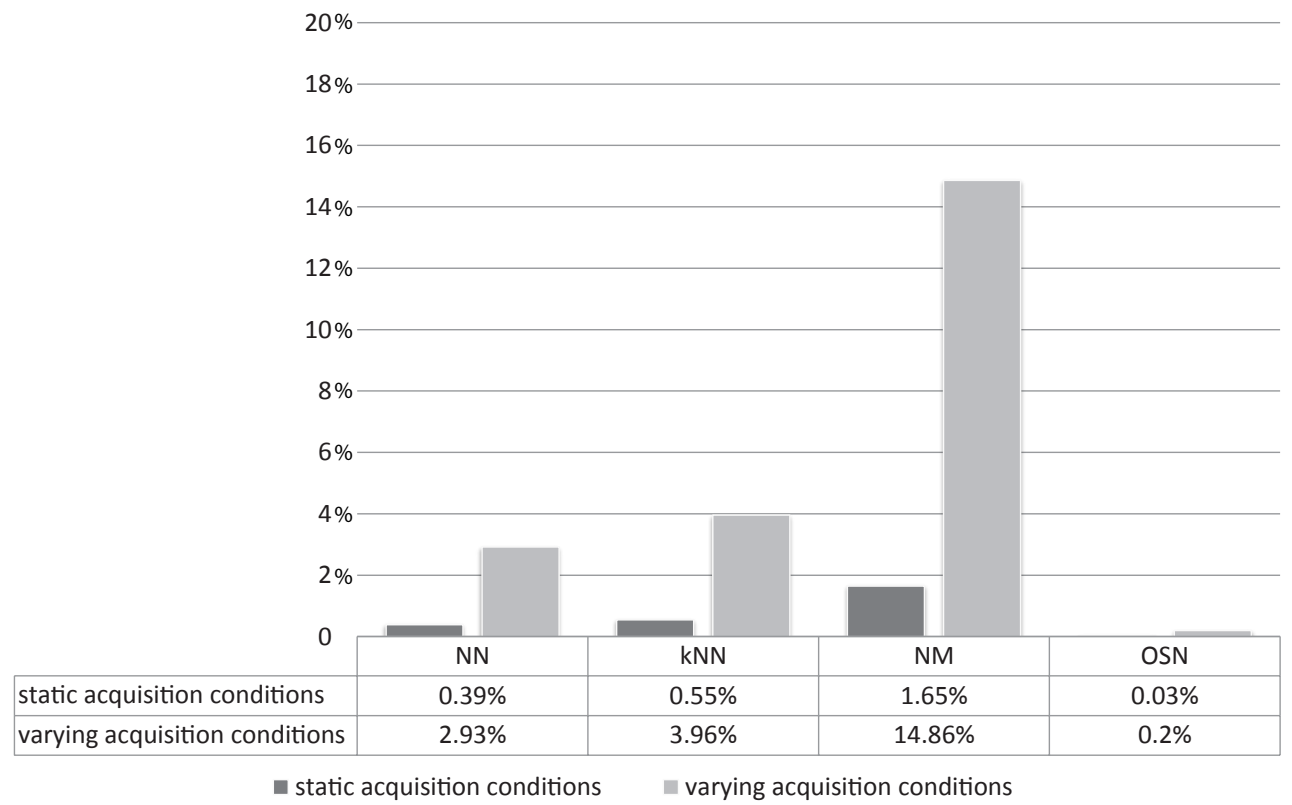

Fig. 3. Averaged level of incorrect recognitions for 500 iterations of the algorithm

\section{Unclassified element level}

In the case of the NN and the NM methods, the algorithms almost always (except for very specific situations) give a classification result. This result can be either correct or incorrect, except for the $\mathrm{kNN}$ and the OSN methods, as these two algorithms can also return a result indicative of a lack of classification. For example, in the kNN method, when $k$ equals 3 and when the nearest neighbors are the objects belonging to three different classes, the algorithm returns a "no classification" result.

Similarly, the optimal spherical neighborhood method will be unable to classify an object, when the feature vector of the object being recognized is outside a sphere of any element belonging to the training set. 
Analyzing the data (Fig. 4) it can be easily noticed that the only method returning a result of no classification is the OSN method. The small percentage obtained in the kNN method seems to be insignificant.

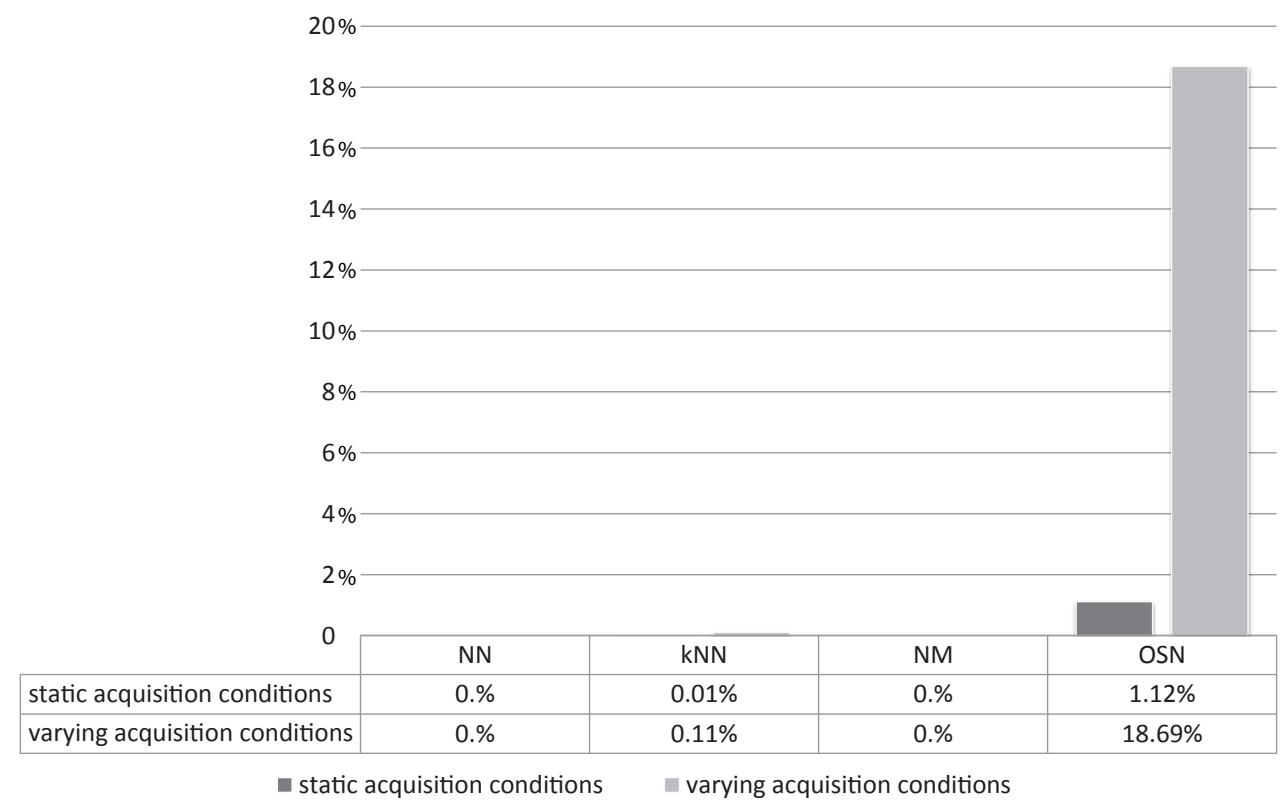

Fig. 4. Averaged level of unclassified objects for 500 iterations of the algorithm

\section{Placement comparison of samples with static and different acquisition conditions in the feature space}

The results indicate worsening the correct classification ratio for pictures taken under different acquisition conditions. It especially affects the methods that use patterns, i.e., the NM and the OSN methods. One of the reasons that may adversely affect the results is a relatively high (when compared to samples photographed under static acquisition conditions) overlapping of the sample classes in the feature space.

The feature space chosen for the investigations had nine dimensions, thus depicting such a situation in a flat figure is impossible. Therefore, Figure 5 presents an exemplary position of the samples in the two-dimensional space. The $\mathrm{Y}$ axis presents the sill value of the variogram for the A channel in the CIELAB color space, while the $\mathrm{X}$ axis the mean grey level on the A channel. The plot shows position of individual feature vectors for rocks photographed under both static and different acquisition conditions. 

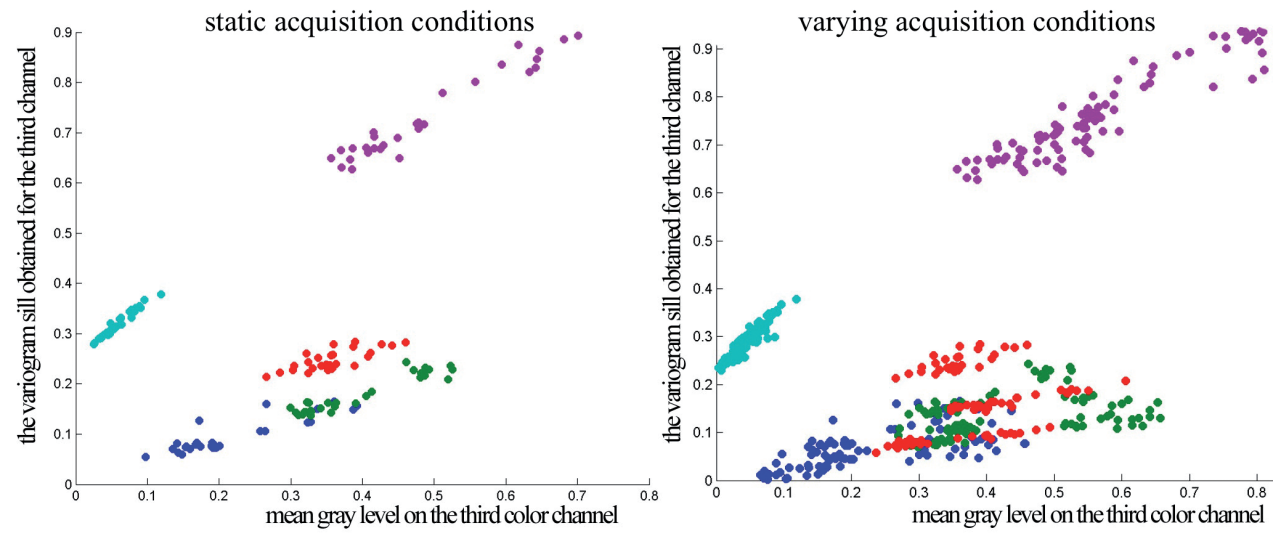

- - granite from Strzelin • - sandstone from Tumlin • - dolomite from Rędziny • - limestone from Czatkowice • - porphyry from Miękinia

Fig. 5. Position of rocks samples photographed under different and static lighting in a two-dimensional feature space

\section{DISCUSSION}

In the automatic object classification the attention is often paid to the impact of image acquisition conditions, especially light settings, on the correctness of classifications (Cabello et al. 2002, Mougiakakou et al. 2005). However, using static acquisition conditions for all pictures is a common practice, which yields the best results in classifying procedures. Examples of the automatic classification of rocks, conducted in the megascopic scale with static laboratory lighting, is presented by Bianconi et al. (2012) and Marshallinger (1997). In the case of the microscopic scale, photographs of thin sections are taken under static lighting conditions and the same setup of polarizers is preserved for every sample (see examples in Marmo 2005 and Młynarczuk et al. 2013). Practically there are no papers that quantitatively describe the effect of changing lighting especially in optical microscopy, on the correctness of rock classification.

\section{Correct recognition level}

The correct classification results of the samples photographed under different acquisition conditions turned out to be satisfactory and even better than initially expected. The correct recognition (Fig. 2) reaches $97.07 \%$ for the NN method. The results obtained for the same samples photographed under static acquisition conditions (99.61\% recognition) are improved only by $2.54 \%$. The difference classification seems to be connected with a worse object class division in the feature space (Fig. 5). 


\section{Incorrect recognition level}

The relatively high number of incorrect recognitions with the NM method deems its use uncertain. The results (Fig. 3) indicate that the most reliable correct classifications is provided with the OSN method. It returned only about $0.03 \%$ and $0.2 \%$ incorrect recognitions of the samples photographed under static and different acquisition conditions, respectively.

\section{"No classification" level}

From the standpoint of the method reliability we can consider correct recognitions and a lack of recognition as the unbiased results (i.e., unburdened with an error), while incorrect recognitions as erroneous results. This approach shows (Fig. 6) that the OSN method yields more desirable results than the NN method, which returned the highest levels of correct results.

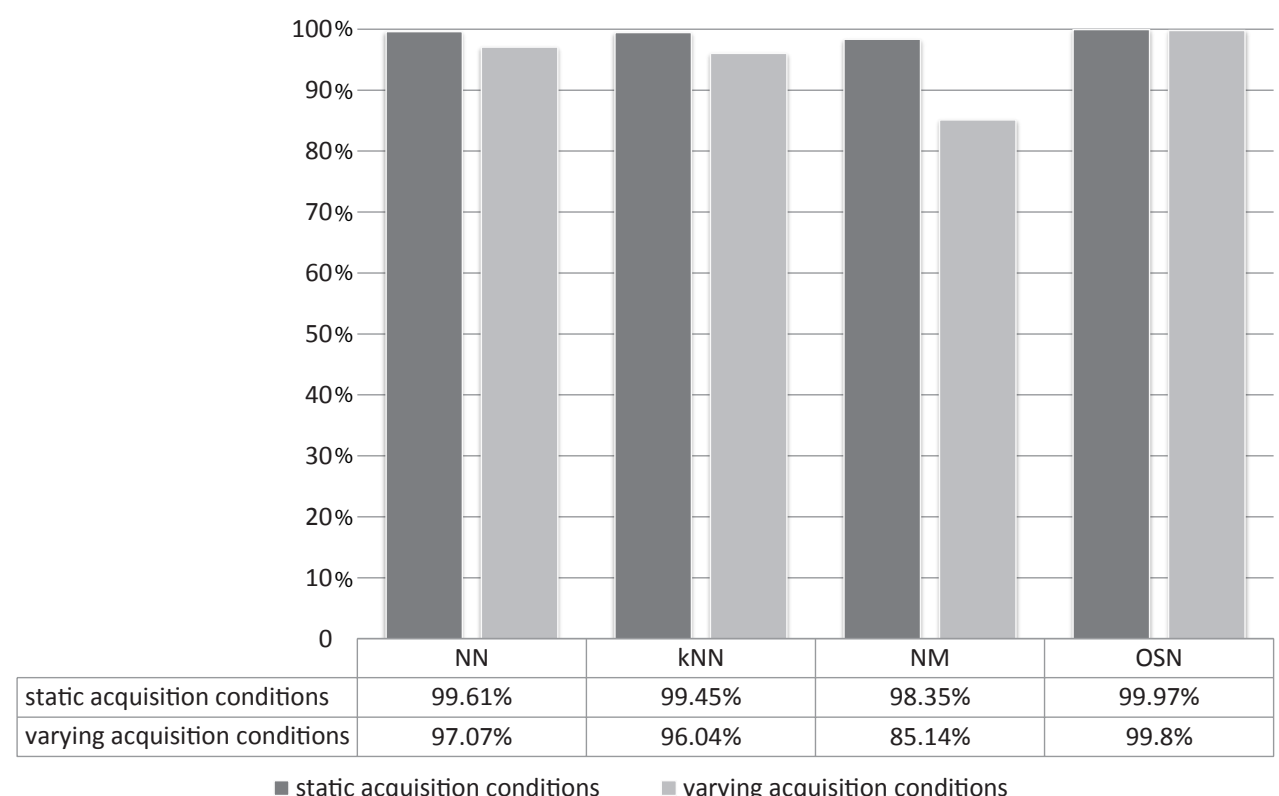

Fig. 6. Averaged level of classifications unburdened with an error for 500 iterations of the algorithm

The OSN method gives more reliable results for samples photographed under different lighting, although it is important to remember that the piece of information returned does not always relates to classifying an object to a specific class. 


\section{Comparison of sample distribution in the feature space}

It is impossible to separate the classes of the objects photographed under different acquisition conditions using linear functions (Fig. 5). These classes in most cases overlap each other. It is especially true for the Strzelin granite, the Tumlin sandstone and the Rędziny dolomite. Analogically, for static acquisition conditions, the same rocks are separated from each other very well. Minimal distance methods yield better results, because they are based on the distance of a recognized sample from each element of the training set, while the methods based on patterns replace the training set with a pattern, which is not sufficiently representative of a given class. Still, it should be noted that Figure 5 shows only two of the nine dimensions of the feature space. The fact that the classes overlap each other in a two-dimensional space, does not necessarily mean that they cannot be separated in a nine-dimensional space. This reasoning only explains the inferior, yet still satisfactory, classification results.

\section{Comparison of the run time of recognition algorithms}

While during a non-automatic classification the time required to recognize the rock has a significant impact because it directly affects work costs of qualified personnel, in the case of the automatic classification it is not a vital economic factor. Algorithm run times are proportional to the amount of computing that must be done during the classification process. The pattern-based methods execute less operations due to the fact that the training set is replaced by a pattern, e.g. the arithmetic mean of a given class. As a result, the shortest classification times were achieved using the NM method. It should be stressed, however, that all presented methods had a classification run times shorter than 1 second for the entire data set composed of 1250 objects subject to recognizing in this paper.

\section{CONCLUSIONS}

The authors checked applicability of pattern recognition methods in automatic rock classification. The investigations of five different rock types were conducted under various lighting and polarization conditions. The methods used show no significant differences in recognizing objects photographed under static and different lighting and polarization conditions. The levels of recognizing the rocks turned out to be better than expected. The most sensitive for lighting and polarization conditions is the NM method, which should be excluded from further work in favor of algorithms.

Although the highest correct recognitions gave the NN method, it seems that the OSN method is safer in terms of returning a correct result (specifically, for samples photographed under different acquisition conditions).

The OSN method returns a relatively high amount of information regarding lack of classification. That is why in creating a universal recognition algorithm a two-phase reconnaissance should be taken into consideration. Combining the OSN method with either of 
the $\mathrm{NN}$ or kNN methods will enable creating an algorithm, which in the case of returning a no classification result could, if acceptable under the study provisions, classify the object, although with a higher risk factor.

\section{REFERENCES}

Bianconi F., González E., Fernández A. \& Saetta A.S., 2012. Automatic classification of granite tiles through colour and texture features. Expert Systems with Applications, 39, $12,11212-11218$.

Cabello E., Sanchez A.M. \& Delgadoz J., 2002. A new approach to identify big rocks with applications to the mining industry. Real-Time Imaging, 8, 1, 1-9.

Dunlop H., 2006. Automatic rock detection and classification in natural scenes. Carnegie Mellon University, Robotics Institute, Pittsburgh [M.Sc. thesis].

Dzwinel K., Haber A. \& Krawiec D., 2006. Zastosowanie samoorganizujących sieci neuronowych Kohoena w klasyfikacji sejsmofacjalnej (rejon Ujkowice - Batycze). Geologia. Kwartalnik Akademii Górniczo-Hutniczej im. Stanisława Staszica w Krakowie, $32,4,441-450$.

Jarzyna J., Opyrchał A. \& Mozgowoj D., 2007. Sztuczne sieci neuronowe dla uzupełnienia danych w geofizyce otworowej - wybrane przykłady. Geologia. Kwartalnik Akademii Górniczo-Hutniczej im. Stanisława Staszica w Krakowie, 33, 4/1, 81-102.

Marmo R., Amodio S., Tagliaferri R., Ferreri V. \& Longo G., 2005. Textural identification of carbonate rocks by image processing and neural network: Methodology proposal and examples. Computers \& Geosciences, 31, 649-659.

Marshallinger R., 1997. Automatic mineral classification in the macroscopic scale. Computers \& Geosciences, 23, 119-126.

Mastej W., 2011. Próba wykorzystania sieci neuronowych w kompleksowej interpretacji danych elektromagnetycznych na przykładzie złoża Grabownica. Geologia. Kwartalnik Akademii Górniczo-Hutniczej im. Stanisława Staszica w Krakowie, 37, 1, 157-173.

Messina A. \& Langer H., 2011. Pattern recognition of volcanic tremor data on Mt. Etna (Italy) with KK Analysis - A software program for unsupervised classification. Computers \& Geosciences, 37, 953-961.

Młynarczuk M., 2010. Description and classification of rock surfaces by means of laser profilometry. International Journal of Rock Mechanics \& Mining Sciences, 47, 138-149.

Młynarczuk M., Górszczyk A. \& Ślipek B., 2013. The application of pattern recognition in the automatic classification of microscopic rock images. Computers \& Geosciences, $60,126-133$.

Mougiakakou S.G., Tsouchlaraki A.T., Cassios C., Nikita K.S., Matsopoulos G.K. \& Uzunoglu N.K., 2005. SCAPEVIEWER: Preliminary results of a landscape perception classification system based on neural network technology. Ecological Engineering, 24, $5-15$. 
Obara B., 2007. Identification of transcrystalline microcracks observed in microscope images of a dolomite structure using image analysis methods based on linear structuring element processing. Computers \& Geosciences, 33, 151-158.

Ślipek B., Mazurkiewicz Ł. \& Oleszko K., 2012. Możliwość wykorzystania metod rozpoznawania obrazów do zastosowań geologicznych na przykładzie automatycznej klasyfikacji zdjęć odsłonięć skalnych. Młodzi naukowcy dla polskiej nauki: materiały Konferencji Młodych Naukowców nt. Wpływ młodych naukowców na osiagnięcia polskiej nauki - Nowe trendy w naukach przyrodniczych, III edycja. Kraków 16.12.2012 r., Creativetime, Kraków.

Tadeusiewicz R. \& Flasiński M., 1991. Rozpoznawanie obrazów. Państwowe Wydawnictwo Naukowe, Warszawa. 